\title{
LEACHABILITY OF ACQ-D AFTER THREE DIFFERENT PRESERVATIVE TREATMENTS
}

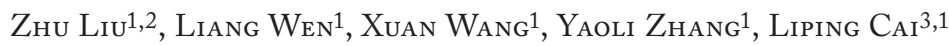 \\ ${ }^{1}$ Nanjing Forestry University \\ China \\ ${ }^{2}$ Guizhou Academy of Forestry \\ CHINA \\ ${ }^{3}$ University of North Texas \\ UsA \\ (Received November 20I9)
}

\begin{abstract}
In this study, the ACQ-D preservative treatments of poplar wood were carried out using the method of living tree injection treatment and the leachability was examined by comparing with the traditional treatment methods, namely, immersion and pressure treatment. In addition, the effects of injection experiment on the soil environment and preservative stability in wood were examined. The results showed that the effect of injection experiment on soil environment around the treated trees was insignificant and the preservative stability of the injection treatment was the best among three methods. ACQ-D preservatives leached easily as the increase of concentration. The retention of preservative after pressure treatment was greater than that of the injection and immersion treatment, but after the leaching tests, three methods had the same preservation grade.
\end{abstract}

KEYWORDS: Living trees injection treatment, immersion treatment, pressure treatment, retention rate, preservative retention.

\section{INTRODUCTION}

Driven by concerns of environmental protection and human health, interest has risen in the development of clear wood preservative treatments to build an environmental-friendly society. Wood has been used as a construction material for thousands of years. Like other cellulose materials, wood suffers from attacked by insects or fungi. Therefore, it is necessary to pre-treat wood with preservatives before using it as building components during their services (Macchioni et al. 2016, Zhang et al. 2016). Wood preservation refers to the treatment of wood products with chemical agents to improve the ability to resist deterioration (Yu et al. 2009). 
Coal tar or olive oil were the main preservatives used in the early stage of wood preservation. The simple preservation process mainly included immersion and brushing during the aged years (Gilbert et al. 1990). Vacuum pressure treatment of wood began in the $19^{\text {th }}$ century, while the use of preservatives was still limited to creosote and coal tar, and the treated wood became darker and smelly. Wood preservatives containing chromium and arsenic (copper, chromium and arsenic) were once the most widely used wood preservatives in the world, but their toxicity to human beings and the environment threatened them, so they were banned at the end of 2003 (Helsen and Bulck 2005). At present, copper-based wood preservatives such as amine-soluble quaternary amine copper (ACQ) have become the most widely used wood preservatives to replace copper, chromium and arsenic (CCA). However, it is likely that the ACQ-treated wood can be well protected from the attacks of insects/fungi to extend its service life. Currently, copper still is the major component in inorganic preservatives for wood preservative treatments.

As a type of wood water-borne preservative, active ingredients in ACQ are soluble in water, so the main drawback of ACQ is its poor leach resistance. Although, copper plays an essential role in protecting wood from attack of fungi, bacteria, insects and antifouling properties. The leaching of ACQ could cause human health problems, such as, liver disease, vomiting, stomach problem and muscle fatigue (Janin et al. 2011). Copper in leached ACQ could also be related to Parkinson disease, being suffered by many aged people in the World. In addition, ACQ does not contain chromium and other chemical components, so it lacks $\mathrm{Cr}^{6+}$ which can oxidize various lignocellulosic groups. Thus, it cannot provide more fixation sites for divalent copper ions, which can lead to the loss of divalent copper ions as active ingredients ( $\mathrm{Li}$ et al. 2006). Although $\mathrm{Cu}^{2+}$ is relatively non-toxic to mammals, it is harmful to aquatic organisms. Studies have found that fish disappear completely when the lake water concentration exceeds $60 \mathrm{ug} \cdot \mathrm{L}^{-1}$ of $\mathrm{Cu}^{2+}$, because this concentration has exceeded the lethal dose of some juveniles (Temiz et al. 2006). $\mathrm{Cu}^{2+}$ also affects microbial populations in soil and sediments. High concentration of copper can inhibit the growth and photosynthesis of algae, affect the permeability of protoplasmic membranes, and make potassium ions lose from cells (Goven et al. 1994). Therefore, to solve the leach of active ingredients in water-borne wood preservatives can not only improve the preservation effect of wood preservatives, but also reduce its impact on the environment and human health. The leach resistance of preservative components is closely related to their degree of fixation in treated wood. This is because the unfixed preservative components in the treated wood are still water-soluble and easily lost to the outside world. The substances produced by a series of chemical reactions with wood components are insoluble in water, so they have better leach resistance (Sun et al. 2010).

As one of the most extensively used wood preservatives currently, alkaline copper quaternary (ACQ) comprises quaternary ammonia and copper oxide (Hasan et al. 2010). There are two common methods to penetrate the ACQ preservative into wood, namely, immersion and pressure treatments. The immersion treatment is to immerse wood in preservatives under the atmospheric pressure/temperature condition, which is a simple operation with low cost. The pressure treatment is to force preservative into the wood through an external pressure, which can deposit high preservative loading in wood after this treatment (Archer et al. 2006). The wood preservation treatment through the preservative injection of living trees is a method to improve the treatment efficiency and reduce the leaching of preservatives (Hill et al. 2004, Günther 1974). This method is to drill or saw holes at the proper parts of the base of the tree, injecting preservative into holes, and bring preservative to the whole tree by means of sap flow of living trees. This method has advantages of simple process, no need factory equipment, less energy consumption and greatly reduced production costs. In plant transplantation and breeding, the injection method is an effective means to rescue the dangerous trees and supplement water and fertilizer of transplanted trees. It can effectively reduce the mortality during transportation and 
after being planted, accelerating their rapid recovery. It is also a means to quantitatively study some physiological processes of plants. Injection method can also be used for pest control, early fertilization, and growth promotion.

The leaching of copper is a major problem to copper-based wood preservatives, including ACQ-D. Under the atmospheric temperature and pressure, the fixation rate of copper preservatives is low and the amount of fixation is limited. Studies have shown that the degree of fixation of copper in preservative-treated wood was affected by factors such as temperature, time and relative humidity (Tascioglu et al. 2008). Therefore, different wood treatments processes such as wood surface treatment, heat treatment and microwave treatment could improve fixation rate (Hansson and Morén 2013). The leaching of preservatives will not only pollute the environment, but also directly affect the preservation efficiency (Tao et al. 2013). In this study, three wood preservative treatment methods, i.e., living tree injection, immersion and pressure treatment were used to preserve-treat poplar wood. The leachability of treated wood was tested, and the change of preservative loading before and after the leaching test was compared. The results can provide a theoretical basis for the research and production of poplar wood preservation.

\section{MATERIALS AND METHODS}

\section{Materials}

Ten years old living poplar trees (Populus L.) were cut from the Nanjing Forestry University Xiashu Forest Farm, Nanjing, Jiangsu Province, China. Tree height was about $10 \mathrm{~m}$ with diameter of about $0.3 \mathrm{~m}$.

Poplar wood samples had an air-dried density of $0.43 \mathrm{~g}^{\mathrm{cm}} \mathrm{cm}^{-3}$ and processed into a size of $20 \times 20 \times 300 \mathrm{~mm}$ (radial $\times$ tangential $\times$ longitudinal), which were used for immersion and pressure treatments.

According to the standard of Wood preservatives - Ammonical copper quat (SB/T 104322007), the preservative used in this study was Didecyl dimethyl ammonium chloride (DDAC) with basic copper carbonate and ethanolamine. There are four types of ACQ according to the proportion of raw materials, components and the different solvents, namely ACQ-A, ACQ-B, ACQ-C and ACQ-D, as shown in Tab. 1.

Tab. 1: ACQ Wood preservative active ingredients.

\begin{tabular}{|l|c|c|c|c|}
\hline \multirow{2}{*}{ Active ingredient } & \multicolumn{4}{c|}{ Index } \\
\cline { 2 - 5 } & ACQ-A & ACQ-B & ACQ-C & ACQ-D \\
\hline $\mathrm{Cu}($ Record with CuO) (\%) & $45.5-54.5(50)$ & $62.0-71.0(66.7)$ & $62.0-71.0(66.7)$ & $62.0-71.0(66.7)$ \\
\hline $\begin{array}{l}\text { Quaternary ammonium salt } \\
\text { (Record with DDAC) (\%) }\end{array}$ & $45.5-54.5(50)$ & $29.0-38.0(33.3)$ & - & $29.0-38.0(33.3)$ \\
\hline $\begin{array}{l}\text { Or Quaternary ammonium salt } \\
\text { (Record with BAC) (\%) }\end{array}$ & - & - & $29.0-38.0(33.3)$ & - \\
\hline
\end{tabular}

The difference between ACQ-A and ACQ-B is that the proportions of $\mathrm{CuO}$ and DDAC in the formulation are different. The content of $\mathrm{CuO}$ in ACQ-B is much higher than that in ACQ$\mathrm{A}$, while the content of DDAC is lower than that in ACQ-A. Its main purpose is to reduce the 
cost of preservatives and improve the effectiveness of preservatives. The disadvantage of ACQ-A and ACQ-B is that the ammonia used as solvent is volatile, which makes that the treated wood has ammonia smell, affecting the operation of workers and polluting environment. Therefore, the ACQ preservative has been greatly improved by using ethanolamine instead of ammonia as a solvent to solve the problem of ammonia volatilization. The improved ACQ preservative is called ACQ-C or ACQ-D, using ethanolamine as a solvent. In this study, the ACQ-D was prepared and diluted with distilled water to three concentrations, namely, $1.5 \mathrm{wt} . \%, 1 \mathrm{wt} . \%$ and $0.5 \mathrm{wt} . \%$.

\section{Injection treatment of living poplar tree}

Three small injection holes were drilled around the tree at a distance of $0.20 \mathrm{~m}$ from the ground. The angle between the injection hole and the longitudinal axis of the tree was $45^{\circ}$. A nail was nailed $1 \mathrm{~m}$ above the injection hole, and the bag containing preservative was hung on the nail as shown in Fig. 1. The valve on the bag was adjusted to drip the preservative liquid at the slowest rate, then the injection needle was inserted into the hole and started injection treatment until the tree stopped absorbing the preservative. Three concentrations (1.5 wt.\%, $1 \mathrm{wt} . \%$ and $0.5 \mathrm{wt} . \%)$ of ACQ-D preservative were injected into trees, respectively. After the preservative injection, the section part of the tree with ACQ-D distribution was cut into $20 \times 20 \times 20 \mathrm{~mm}$ samples. Six samples were taken from each tree and weighed as $T_{1}$, respectively, while the samples without injection treatment were marked as $\mathrm{T}_{1}$.

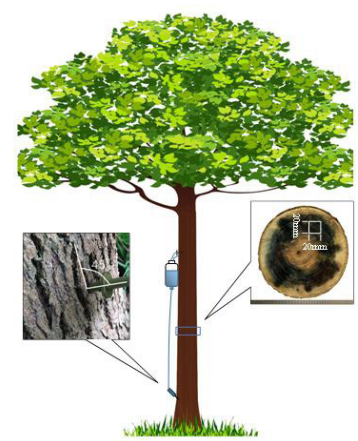

Fig. 1: Process of injecting $A C Q-D$ and sample collecting.

\section{Immersion treatment of poplar wood samples}

The test poplar tree for the immersion treatment was selected from the same location and had the same age and similar size with the injection-treated trees, but grew up without any preservative treatment. The wood samples were cut from the tree and placed in the treatment tank, the ACQ-D preservative was added and glass blocks were placed on the test wood samples to make the samples completely immersed in the liquid preservative, and the opening of the tank was sealed with a plastic film. After $72 \mathrm{~h}$ immersion, the test wood samples were taken out and the wood surface was wiped with filter paper. Six test wood samples were treated with each ACQ-D concentration. After the immersion treatment, at the distance of $120 \mathrm{~mm}$ in the longitudinal direction of each test wood sample, three samples $(20 \times 20 \times 20 \mathrm{~mm})$ were continuously taken out and weighed as $\mathrm{T}_{2}$, respectively. The samples without immersion treatment were weighted and marked as $\mathrm{T}_{2}$. 


\section{Pressure treatment of poplar test wood}

Test wood samples were cut from the non-preservative-treated poplar tree and placed in a sealed treatment tank, then, the tank was vacuumed to $0.08-0.09 \mathrm{MPa}$ for $30 \mathrm{~min}$ and added ACQ-D preservative, pressurized to $0.8 \mathrm{MPa}$ and kept for 3 hours. After the pressure released, the tank was vacuumed again to $0.08-0.09 \mathrm{MPa}$ for $10 \mathrm{~min}$ to drain out the excess preservative in the samples. After the pressure treatment, the test wood samples were taken out, and wiped the wood surfaces with filter paper. Six test wood samples were treated with each ACQ-D concentration. After the pressure treatment, at the distance of $120 \mathrm{~mm}$ in the longitudinal direction of each test sample, three samples $(20 \times 20 \times 20 \mathrm{~mm})$ were continuously taken and weighed $\mathrm{as}_{3}$, respectively. The samples without pressure treatment were weighted and marked as $T_{3}$.

\section{Environmental quality assessment of living tree injection treatment}

Before and after the preservative injections, the soil around the tree roots was taken to detect the contents of heavy metals, e.g., copper, in which, sixty soil samples were obtained for each tree. Based on the standard of determination of available in forest soil (LY/T 1260-1999), the copper content in the soil was measured accordingly. According to the standard of Environmental quality standard for soils (GB15618-1995), the soil quality was examined before and after the preservative injections. Ten gram soil sample was dried in an oven with a temperature of $103^{\circ} \mathrm{C}$ for $24 \mathrm{~h}$, placed in a bottle with $50.0 \mathrm{~mL}$ of 0.1 mol.L-1 hydrochloric acid and shaken for $1.5 \mathrm{~h}$ with a vibration machine, then the clear liquid was achieved by filtering the soil. Using an atomic absorption spectrometer, the copper concentration was examined and the soil copper content was calculated by Eq. (1):

$$
\mathrm{M}_{\mathrm{Cu}}=\mathrm{c} \times \mathrm{r}
$$

where: $M_{C u}$ is the calculated soil copper content, $\left(\mathrm{mg}^{\mathrm{kg}} \mathrm{kg}^{-1}\right)$; $\mathrm{c}$ is the copper concentration measured by the Atomic absorption spectrometry, (ug. $\left.\mathrm{mL}^{-1}\right) ; r=$ (milliliter quantity of extracting agent)/ (soil weight) ${ }^{-1}$.

\section{ACQ-D Leaching rate tests}

Based on the standard Method for accelerated evaluation of preservative leaching (AWPA E11-16) and the Standard laboratory method of determining the leachability of wood preservatives (GB/T 29905-2013), for each preservative treatment case, six preservative-treated samples were immersed in a $500 \mathrm{ml}$ beaker with distilled water that was stirred using a magnetic stirrer. The distilled water in the beaker was substituted by fresh water every $6 \mathrm{~h}, 24 \mathrm{~h}, 48 \mathrm{~h}$ and then freshsubstituted every $48 \mathrm{~h}$ for 14 days. Using the Atomic absorption spectrometry, the copper content of each test was determined. The ACQ-D leaching rate was calculated according to Eq. (2):

$$
\mathrm{L}=\left(\frac{0.18 \times c_{1}}{c \times m_{G} \times 1000}\right) \times 100 \%
$$

where: $c_{1}$ is the copper concentration in the determined filtrate, $\left(\mathrm{mg} \cdot \mathrm{L}^{-1}\right) ; c$ is the mass fraction of components to be measured in ACQ-D preservative (66.7\% for ACQ-D) (\%); $m_{G}$ is the quantity of absorbed ACQ-D of sample in preservation treatment $\left(\mathrm{T}_{\mathrm{i}}-\mathrm{T}_{\mathrm{i}}, \mathrm{i}^{\mathrm{i}}=1,2,3\right),(\mathrm{g})$

\section{ACQ-D loading measurement}

Based on the standard methods for the analysis of waterborne wood preservatives (GB/T 23229-2009), before and after the leaching tests, the different preservative loadings were 
examined. The powder samples were obtained by grinding the wood specimens with different treatments and oven-dried at $103^{\circ} \mathrm{C}$ for $24 \mathrm{~h}$. The $0.5 \mathrm{~g}$ powder sample in the beaker that had $30 \mathrm{ml}$ distilled water and $5.0 \mathrm{~g}$ concentrated sulfuric acid was heated to $75^{\circ} \mathrm{C}$, held this temperature and shacked for $30 \mathrm{~min}$ for dissolving the powder sample. Then the solution with dissolved powder was poured into a $200 \mathrm{ml}$ flask with distilled water for filtration. The filtrate elements from the filtration was examined using the Atomic Absorption Spectrometry and the preservative loadings of copper in wood specimens were estimated according to Eq. (3):

$$
R_{C u}=0.2 \times c_{2} \times d / W_{1}
$$

where: $R_{C u}$ is the total copper loading of the preservative, $\left(\mathrm{kg} \cdot \mathrm{m}^{-3}\right) ; c_{2}$ is the concentration of preservative in the filtrate that was measured using the Atomic Absorption Spectrometry, $\left(\mathrm{mg} \cdot \mathrm{L}^{-1}\right) ; \mathrm{d}$ is the density of wood specimen, $\left(\mathrm{g} \cdot \mathrm{cm}^{-3}\right) ; W_{1}$ is the amount of powder, $(\mathrm{g})$.

\section{EDX analysis}

The leaching test samples $(20 \times 20 \times 20 \mathrm{~mm})$ were cut into two parts $(20 \times 20 \times 10 \mathrm{~mm}$ each). One part of the sample was examined by EDX before the leaching test and the other one was examined by EDX after the leaching test to observe the effect of the leaching test on the preservative loading. Three kinds of preservation-treated samples with different concentrations were sliced by the slicing machine. The transverse section was observed and the thickness of the section was $20 \mathrm{um}$. All the sections to be observed were sprayed with a layer of metal by a vacuum coater to increase conductivity. Then the section was observed by the Quanta 200 Scanning electron microscopy energy dispersive spectrometer (EDX). The acceleration voltage was $15 \mathrm{kV}$ and the working distance was $13 \mathrm{~mm}$.

\section{RESULTS AND DISCUSSION}

\section{Environmental quality assessment of living tree injection treatment}

The flow of preservative in the tree trunk is mainly driven by transpiration of leaves. Since wood is a porous material, there are many small gaps among wood cells. Thus, the ACQ-D preservative went upward to the tree-top direction at daytime due to the transpiration, while it also flowed downward to the root direction at night time due to the condensation, which might cause the tree roots to contain a certain amount of preservatives. As a result, the ACQ-D preservatives could pollute the soil around the treated tree. Thus, it is necessary to test whether this injection treatment would cause environmental pollution. Based on the standard of soil environmental quality (GB/T 15618-1995), there are three grades of soil according to their $\mathrm{pH}$ values. In this study, the $\mathrm{pH}$ values of the soil around the preservative injected trees were range from 6.71 to 7.38, which was specified to be the acidic grade. Based on the standard of GB156181995, it was classified into type II soil, which designated that the soil quality was basically not harmful and pollution for plants and the environment.

As shown in Fig. 2, such as 1.5 wt.\% ACQ-D treated samples, the experimental results indicated that, before the preservative injection, the soil copper contents were ranged from 41.6 to $67.1 \mathrm{mg} \cdot \mathrm{kg}^{-1}$, while after the preservative injections the copper contents were between 61.1 and $89.1 \mathrm{mg} \cdot \mathrm{kg}^{-1}$. For $1 \mathrm{wt} . \%$ and $0.5 \mathrm{wt} . \%$ ACQ-D treated samples, the copper contents were $55.5-81.2 \mathrm{mg} \cdot \mathrm{kg}^{-1}$ and $43.9-79.7 \mathrm{mg} \cdot \mathrm{kg}^{-1}$. A slight increase in soil copper content was observed before and after the injection treatment. However, soil copper contents after the injection treatments were still lower than the acceptable value (i.e. $100 \mathrm{mg} \cdot \mathrm{kg}^{-1}$ ) for type II soil specified by the standard of GB15618-1995, which indicated that the preservative injection insignificantly 
Vol. 65 (4): 2020

affect the soil environment. This acceptable value (i.e. $100 \mathrm{mg}^{\mathrm{k}} \mathrm{kg}^{-1}$ ) was also confirmed by Yang et al. (2007), which suggested that the low concentration of copper $\left(<100 \mathrm{mg} \cdot \mathrm{kg}^{-1}\right)$ in soil would benefit the growth of trees.
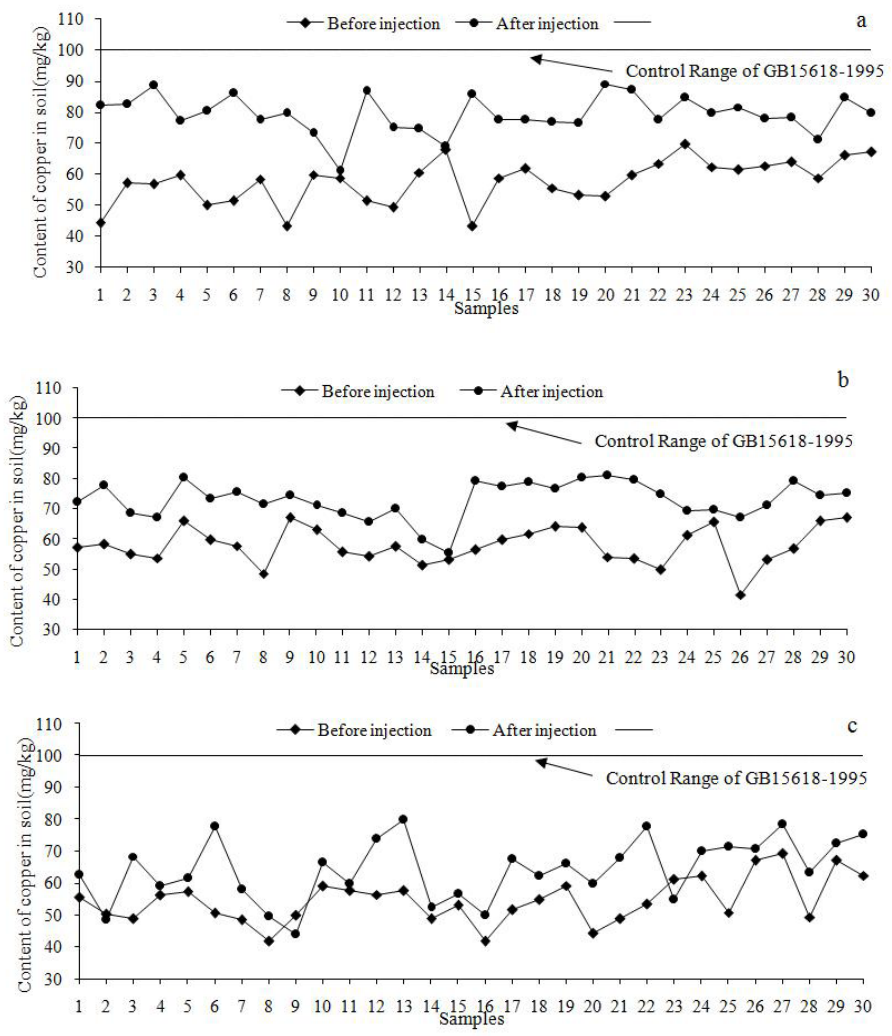

Fig. 2: Changes of copper content in soil before and after injection treatments: (a) 1.5 wt.\% ACQ, (b) $1.0 w t . \% A C Q$ and (c) $0.5 w t . \% A C Q$.

\section{Leaching of ACQ-D with different preservation treatments}

The leaching rates of ACQ-D with time using the three preservative treatment methods, namely, injection, immersion and pressure treatments are presented in Fig. 3. The curves of the treated wood during the leaching process could be divided into three different stages. In the early stage $(0-24 \mathrm{~h})$, the leaching rate of ACQ-D all increased significantly throughout this stage, which was the main period of leaching, showing that the large amount components of ACQ-D leached from the treated wood. The reason was that ACQ-D was a waterborne preservative, and the effective components of ACQ-D would leach with the water during the service of the wood products after the preservation treatment (Lin et al. 2009). In the second stage (24-96 h), the leaching rate began to decrease. In the last stage (after $96 \mathrm{~h}$ ), the leaching rate was progressively reduced and approached to zero as shown in Fig. 3. The reason may be described as follows. The fixation state of ACQ-D could be divided into physical fixation and chemical fixation. Through the physical fixation, such as the dipole-dipole and ion-dipole interaction between cellulose and 
copper in ACQ-D (Yu et al. 2011), the preservatives in the wood were easy to leach with the water evaporation and the change of environments. The copper in ACQ-D reacted with hemicellulose and lignin in a chemically bonded manner. This fixation state made the preservative more stable in the wood and had a better antiseptic effect (Zhang and Kamdem 2000).

For three different preservative treatment methods, the leaching rate of ACQ-D after injection treatment was lower than that of the immersion treatment and pressure treatment. At the same time, the concentration of the preservative also affected its fixation in wood. As shown in Fig. 3, the preservative would be easier to leach with the increase of concentration. This result also had a good agreement with the results of published articles (Liu et al. 2019, Yu et al. 2015).
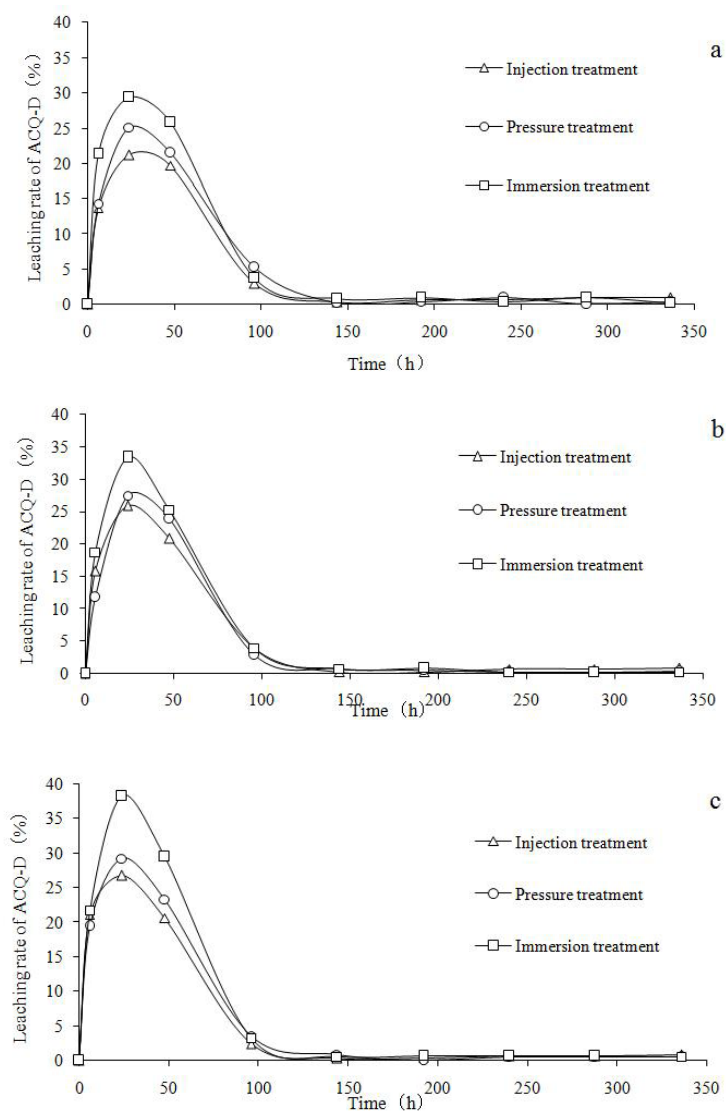

Fig. 3: Leach rate of $A C Q-D$ after three different preservative treatments: (a) 0.5 wt.\% $A C Q$, (b) $1.0 w t . \% A C Q$ and (c) 1.5 wt.\% ACQ).

\section{Retention of preservative in wood}

Preservative retention is an important index for evaluating wood preservation consequence and also the basis for classifying the use grade of wood preservation. The preservative retention of three different treatments before and after the leaching tests are shown in Tab. 2. As shown in the table, it can be seen that the higher the concentration, the greater the preservative retention can be achieved, which was caused by the active ingredients contained in ACQ-D. Before 
leaching tests, such as $1.5 \mathrm{wt} . \%$ concentrations of ACQ-treated samples, preservative retention of pressure treatment was the highest, which can reach $4.89 \mathrm{~kg} \cdot \mathrm{m}^{-3}$. According to the standard of GB/T 31761-2015 Alkaline copper quat (ACQ) of preservative pressure-treated wood, the wood treated by this method can meet the requirements of Grade $\mathrm{C} 4$. The preservative retention of injection treatment and immersion treatment were $3.78 \mathrm{~kg} \cdot \mathrm{m}^{-3}$ and $3.85 \mathrm{~kg} \cdot \mathrm{m}^{-3}$, respectively, which could meet the requirements of Grade $\mathrm{C} 3$. However, preservative retention of the pressuretreated wood after leaching test was reduced to $3.07 \mathrm{~kg} \cdot \mathrm{m}^{-3}$, and the loss amount of preservative was the most one among three methods. The preservative retention of immersion and injection treatments after leaching tests were $3.11 \mathrm{~kg} \cdot \mathrm{m}^{-3}$ and $3.16 \mathrm{~kg} \cdot \mathrm{m}^{-3}$, respectively, which could still meet the requirements of Grade $\mathrm{C} 3$. The same trends could be found for the samples treated with 1 wt. $\%$ and 0.5 wt. $\%$ concentrations of ACQ-D, but preservative retention decreased slightly. Therefore, it could be seen that after leaching tests, preservative retention for three treatment methods reached the same grade, and injection treatment method could make the ACQ-D more stable in wood.

Tab. 2: Preservative retention of different preservative treatments.

\begin{tabular}{|c|c|c|c|}
\hline Preservation treatment & $\begin{array}{c}\text { Concentration } \\
\text { (wt.\%) }\end{array}$ & $\begin{array}{c}\text { Retention of preservative } \\
\text { before leaching }\left(\mathrm{kg} \cdot \mathrm{m}^{-3}\right)\end{array}$ & $\begin{array}{c}\text { Retention of preservative } \\
\text { after leaching }\left(\mathrm{kg} \cdot \mathrm{m}^{-3}\right)\end{array}$ \\
\hline \multirow{3}{*}{ Injection treatment } & 1.5 & 3.78 & 3.16 \\
\cline { 2 - 4 } & 1 & 2.96 & 2.35 \\
\cline { 2 - 4 } & 0.5 & 1.67 & 1.42 \\
\hline \multirow{3}{*}{ Immersion treatment } & 1.5 & 3.85 & 3.11 \\
\cline { 2 - 4 } & 1 & 2.81 & 2.11 \\
\cline { 2 - 4 } & 0.5 & 1.51 & 1.09 \\
\hline \multirow{3}{*}{ Pressure treatment } & 1.5 & 4.89 & 3.07 \\
\cline { 2 - 4 } & 1 & 3.66 & 2.47 \\
\cline { 2 - 4 } & 0.5 & 2.38 & 1.67 \\
\hline
\end{tabular}

\section{EDX analysis}

Copper is the major component in ACQ-D preservative to protect wood against the attacks of insects and/or fungi. The copper content examination can be helpful for evaluation of the efficiency of wood preservation treatment. This experiment mainly investigated the leaching of preservative after different preservation treatments, the EDX examination of only $1.5 \mathrm{wt} . \%$ concentration preservative after treatment is illustrated as an example (Fig. 4).

As sown in Fig. 4, after the preservation treatment, the ACQ-D preservative entered the wood cell wall and the distribution of copper was not even, in which, some parts were concentrated. Previous research also confirmed this result (Liu et al. 2019). It can be found that the distribution of copper in the cell wall changed after leaching test. In addition, after leaching test, the content of copper decreased, especially under the pressure treatment. The atomic percentage of copper in the cell wall was examined by EDX (Tab. 3) and it was shown that the content of copper decreased from $51.1 \%$ to $17.8 \%$. Compared with the pressure treatment, the copper was more stable after the injection treatment, followed by the immersion treatment. This trend was basically consistent with the results of the preservative retention tests.

Leaching of copper is a major problem to copper-based wood preservatives, including ACQ-D. At room temperature and under normal pressure, the fixation rate of copper wood preservatives was slow and the amount of fixation was limited. Studies have shown that the 
degree of fixation of copper in preservative wood is affected by factors such as temperature, time and relative humidity (Ye and Morrell 2015). Therefore, different post wood treatments such as wood surface treatment, heat treatment and microwave treatment can effectively improve fixation rate (Ahmed et al. 2013) .

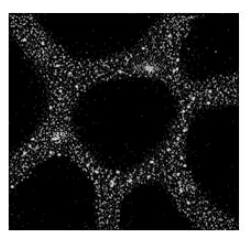

Before leaching test (Pressure treatment) $\downarrow$

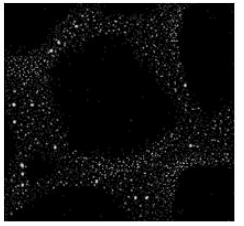

Before leaching test (Immersion treatment)

$\downarrow$

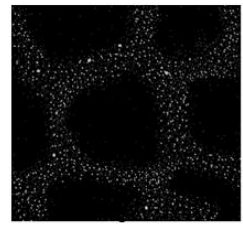

Before leaching test (Injection treatment)

$\downarrow$

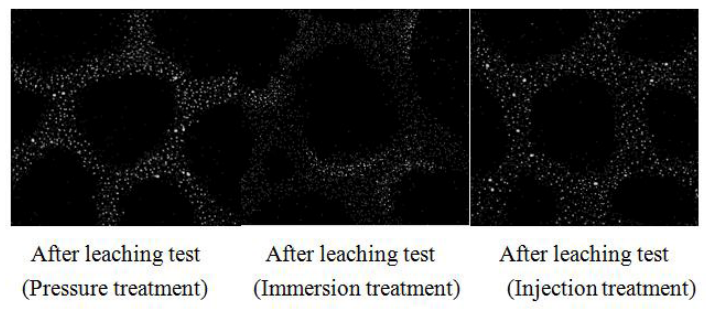

Fig. 4: EDX imagies of 1.5 wt.\% ACQ-D treated samples.

Tab. 3: Percentage of Cu element content before and after leach test.

\begin{tabular}{|c|c|c|c|c|}
\hline \multicolumn{2}{|c|}{ Concentration of ACQ-D } & Pressure treatment & Immersion treatment & Injection treatment \\
\hline \multirow{2}{*}{$1.5 \%$} & Before leaching & $51.1 \%$ & $31.2 \%$ & $36.7 \%$ \\
\cline { 2 - 5 } & After leaching & $17.8 \%$ & $15.6 \%$ & $16.9 \%$ \\
\hline \multirow{2}{*}{$1 \%$} & Before leaching & $28.6 \%$ & $19.5 \%$ & $21.6 \%$ \\
\cline { 2 - 5 } & After leaching & $13.1 \%$ & $12.2 \%$ & $14.8 \%$ \\
\hline \multirow{2}{*}{$0.5 \%$} & Before leaching & $22.3 \%$ & $10.6 \%$ & $11.7 \%$ \\
\cline { 2 - 5 } & After leaching & $8.6 \%$ & $6.3 \%$ & $7.2 \%$ \\
\hline
\end{tabular}

\section{CONCLUSIONS}

Poplar wood and trees were treated by three different preservation treatment methods. In the preservative leaching tests, the leaching rate of ACQ-D after injection treatment was lower than that of immersion and pressure treatments. The higher the concentration of the solution, the easier it would leach. Before the leaching test, the preservative retention of poplar wood treated by the pressure treatment was the highest, but after the leaching test, the preservative retention of samples treated by three preservation treatment methods reached the same grades. After the EDX analysis, it was found that the distribution of copper in cell wall changed after the leaching test. In addition, after the leaching test, the content of copper decreased, especially for the pressure treatment. The examination of the soil around the injection-treated tree before and after treament indicated that the living tree preservative injection treatment did not cause significant quality change for the soil environment. 


\section{ACKNOWLEDGMENTS}

The authors are grateful for the financial supports of the National Natural Science Foundation of China (grant number: 31670558) and National Key Research and Development Program of China (grant number: 2017YFD0600202)

\section{REFERENCES}

1. Ahmed, S.A., Hansson, L., Morén, T., 2013: Distribution of preservatives in thermally modified Scots pine and norway spruce. Wood Science and Technology 47(3): 499-513.

2. Archer, K., Lebow, S., Walker, J., 2006: Wood preservation. In: Primary Wood Processing. Pp 297-338, Springer Netherlands.

3. Gilbert, F.I., Minn, C.E., Duncan, R.C., Wilkinson, J., 1990: Effects of pentachlorophenol and other chemical preservatives on the health of wood-treating workers in Hawaii. Archives of Environmental Contamination \& Toxicology 19(4): 603-609.

4. Goven, A.J., Chen, S.C., Fitzpatrick, L.C., Venables, B.J., 1994: Lysozyme activity in earthworm (Lumbricus terrestris) coelomic fluid and coelomocytes: Enzyme assay for immunotoxicity of xenobiotics. Environmental Toxicology and Chemistry 13(4): 607-613.

5. Günther B., 1974: Aspects, results and trends in wood preservation, an interdisciplinary science. Wood Science and Technology 8(3): 163-183.

6. Hasan, A.R., Hu, L., Solo-Gabriele, H.M., Fieber, L., Cai, Y., 2010: Townsend, T.G. Field-scale leaching of arsenic, chromium and copper from weathered treated wood. Environmental Pollution 158(5): 1479-1486.

7. Helsen, L., Bulck, E.V.D., 2005: Review of disposal technologies for chromated copper arsenate (CCA) treated wood waste, with detailed analyses of thermochemical conversion processes. Environmental Pollution 134(2): 310-314.

8. Hill, C.A.S., Papadopoulos, A.N., Payne, D., 2004: Chemical modification employed as a means of probing the cell-wall micropore of pine sapwood. Wood Science and Technology 37(6): 475-488.

9. Janin, A., Coudert, L., Riche, P., Mercier, G., Cooper, P., Blais, J.F., 2011: Application of a cca-treated wood waste decontamination process to other copper-based preservativetreated wood after disposal. Journal of Hazardous Materials 186(2-3): 1880-1887.

10. Li, G., Nicholas, D.D., Schultz, T.P., 2006: Effect of delayed drying time on copper distribution in the annual rings of ACQ-treated southern yellow pine research stakes. Forest Products Journal 56(3): 29-31.

11. Lin, L.D., Chen, Y.F., Wang, S.Y., Tsai, M.J., 2009: Leachability, metal corrosion, and termite resistance of wood treated with copper-based preservative. International Biodeterioration \& Biodegradation 63(4): 533-538.

12. Liu, Z., Wang, X., Zhang, Y.L., Wen, L., Zheng, L., Cai, L.P., 2019: Flow rate and fixation of ACQ-D preservative in poplar living tree after injection. Wood Science and Technology 53(2): 1-19.

13. Liu, Z., Wang, X., Zhang, Y.L., Wen, L., Zheng, L., 2019: Distribution and fixation of ACQ-D in young poplar living tree. Journal of Fujian Agriculture and Forestry University (Natural Science Edition) 48(1): 35-40.

14. Macchioni, N., Pizzo, B., Capretti, C., 2016: An investigation into preservation of wood from Venice foundations. Construction and Building Materials 111: 652-661. 
15. Sun, Q.F., Yu, H.P., Liu, Y.X., Li, J., Lu, Y., Hunt, J.F., 2010: Improvement of water resistance and dimensional stability of wood through titanium dioxide coating. Holzforschung 64(6): 757-761.

16. Tao, W., Shi, S., Kroll, C.N., 2013: Influences of wood preservation, lumber size, and weather on field leaching of red pine lumber. Journal of Hazardous Materials 260: 296-304.

17. Tascioglu, C., Cooper, P.A., Ung, T., 2008: Effects of fixation temperature and environment on copper speciation in ACQ treated red pine. Holzforschung 62(3): 289-293.

18. Temiz, A., Yildiz, U.C., Nilsson, T., 2006: Comparison of copper emission rates from wood treated with different preservatives to the environment. Building and Environment 41(7): 910-914.

19. Yang, H.F., Yan, M., Yao. J., Wang, Y.B., Liu, D.Y., 2007: Impact of $\mathrm{Cu}$ and $\mathrm{Zn}$ pollution on rape growth and soil enzyme activity. Chinese Journal of Applied Ecology 18(7): 1484-1490.

20. Ye, M., Morrell, J.J., 2015: Effect of post-treatment processing on copper migration from Douglas-fir lumbertreated with ammoniacal copper zinc arsenate. Journal of Environmental Management 152: 268-272.

21. Yu, L.L., Cao, J.Z., Cooper, P.A., Ung, Y.T., 2009: Effect of hot air post-treatments on copper leaching resistance in ACQ-D treated Chinese fir. European Journal of Wood and Wood Products 67(4): 457-463.

22. Yu, L.L., Cao, J.Z., Gao, W., Su, H., 2011: Evaluation of ACQ-D treated Chinese fir and Mongolian Scots pine with different post-treatments after 20 months of exposure. International Biodeterioration \& Biodegradation 65(4): 585-590.

23. Yu L.L., Tang, Z.Z., Ma, X.J., Zhu, L.Z., 2015: Evaluation of the correlations between copper stabilization and valence conversion on copper leaching from ACQ-D treated wood. Wood Research 60(5): 697-705.

24. Zhang, J., Kamdem, D.P., 2000: Interaction of copper-amine with southern pine: retention and migration. Wood \& Fiber Science 32(3): 332-339.

25. Zhang, Z.L., Yang, T., Mi, N., Wang, Y., Li, G.Y., Wang, L.H., Xie, Y.J., 2016: Antifungal activity of monoterpenes against wood white-rot fungi. International Biodeterioration \& Biodegradation 106: 157-160.

\author{
Zhu LiU \\ 1Nanjing Forestry University \\ College of Material Science and Engineering \\ NANJING 210037 \\ P. R. China \\ ${ }^{2}$ Guizhou Academy of Forestry \\ Guiyang 550000 \\ P.R. Chnia \\ Liang Wen, Xuan Wang, Yaoli Zhang* \\ Nanjing Forestry University \\ College of Material Science and Engineering \\ NANJING 210037 \\ P. R. China \\ *Corresponding author: zhangyaoli@126.com
}




\section{Liping CAi \\ 1University of North Texas \\ Denton, Texas \\ UsA}

${ }^{2}$ Nanjing Forestry University

College of Material Science and Engineering

NANJING 210037

P. R. ChinA 
